\title{
Changes of Growth and Nutrient-relating Enzymatic Activities of Sargassum thunbergii When Exposed to Different Nutrient Conditions
}

\author{
Yong Liu \\ Haibohe Sewage Treatment Plant, Qingdao, Shandong Province, 266003, China \\ E-mail: yong.liu@qdvw.com
}

\begin{abstract}
Haili Tan (Corresponding author)
Harbin Institute of Technology at Weihai, Weihai, Shandong Province, 264200, China

E-mail:wawa_thl@sina.cn
\end{abstract}

Received: January 5, 2014 Accepted: February 9, 2014 Published: July 1, 2014

doi:10.5296/ast.v2i2.5103 URL: http://dx.doi.org/10.5296/ast.v2i2.5103

\begin{abstract}
Macroalgae have been suggested to play an important role in seawater decontamination. It is reported that Sargassum thunbergii has been one of the dominant macroalgal species of the intertidal zone along the coastal Shandong Province. However, serious degradation has occurred because of the pollution and the deterioration of seawater quality. The purpose of the present study was to study the growth changes of $S$. thunbergii when exposed to different nutrient conditions, and the possible effective mechanism basing on nutrient-relating enzymatic activity was studied. Result showed that: (1) The relative growth rate (RGR) of $S$. thunbergiiis varied greatly when exposed to different nutrient conditions, and its fresh weight in the treated group was significantly inhibited as compared to that in the control. It seemed that high concentration of phosphate had more obviously inhibitory effect on growth of $S$. thunbergii as compared to the effect of nitrate changes. Moreover, the concentrations of phosphate and nitrate fluctuated with time and concentration increasing, inferring the mechanism of absorption and release might co-existe in S. thunbergii. (2) The activity of Nitrate reductase (NR) increased with the increment of the environmental nitrate concentration, but relatively higher $\mathrm{N}: \mathrm{P}$ ration (32:1) significantly inhibited its activity. Alkaline Phosphatase (AKP) increased with the increment of the environmental phosphate
\end{abstract}




\section{Macrothink}

Aquatic Science and Technology ISSN 2168-9148 2014, Vol. 2, No. 2

concentration in groups of 0 and $2.5 \mu \mathrm{mol} / \mathrm{L}$, but decreased adversely with concentration increment in groups of $16 \mu \mathrm{mol} / \mathrm{L}$ and $80 \mu \mathrm{mol} / \mathrm{L}$. Results in the present study demonstrated a significant effect of environmental nutrient conditions on growth of $S$. thunbergiiis and a co-existent mechanism of absorption and release of nitrate and phosphate was suggested in $S$. thunbergiiis.

Keywords: Nutrient condition, Nitrate/phosphate ratio, Nitrate reductase (NR), Alkaline phosphatase (AKP) 


\section{Introduction}

There has been a growing awareness worldwide of the problems associated with red tides, which cause serious destruction to the coastal marine environment and massive mortality of cultured fish (Anderson, 1997). Extensive research has been undertaken to manage blooms using physical and chemical methods, but the potential ecological impact is a big obstacle to implementation. Biological strategies thus are suggested because of their environment-friendly features (Jeong et al., 2000). One of the most promising of control techniques is applying seaweeds as the potential algicide sources, which are abundant and represents an easy, low cost and relatively environmentally benign. Two main mechanisms are thought to involve in the impact of seaweed in bloom mitigation. One is through allelopathic pathway; the other is through nutrient competition, which could effectively decrease the nutrient resource availability for microalgal growth (Zhang et al., 2009).

Eutrophication is suggested to be the material basis of red tide in coastal area. It's the combinational effects of physical (temperature, light and turbulence), chemical (nitrogen, phosphate, heavy metal, $\mathrm{pH}$, dissolved oxygen and $\mathrm{CO}_{2}$ etc) and biological factors, among which nutrient is thought be the most essential factor resulting in eutrophication. Nitrogen and phosphate are the massive nutrient necessary for the growth of marine plants including seaweeds. Seaweeds absorb nutrients and assimilates into nutritional ingredients itself needs. This procedure would benefit to alleviating the eutrophication and playing essential role in material cycle and transformation in marine environment and therefore, is suggested to be widely used in bloom mitigation and water purification (Chung et al., 2002).

S. thunbergiiis, a common sargassum species, distributed in intertidal zone or below-tidal zone. It is an important economic resource for industrial extraction and bait for holothurians and abalone aquaculture. S. thunbergii is also the spawning and feeding refuge for crabs, mollusks, and clam worm in tidal and subtidal area. We thus performed the present study to examine the responses of $S$. thunbergiiis when exposed to different nutrient conditions. The purpose of the study aims at elucidating the absorption and alleviating ability of $S$. thunbergiiis on the environmental nutrients as a potential candidate for marine eutrophicaiton mitigation.

\section{Materials and Methods}

\subsection{Macroalgal Collection and Cultivation}

The frond of Sargassum thunbergii (Mertens) O'Kuntze(s. thunbergii) were collected from intertidal zone of Taiping Cape, Qingdao, Shandong Province, China. The thalli were collected separately in $500 \mathrm{ml}$ sterile bottles filled with sterile seawater and then immediately transported to the laboratory in glass containers. To remove any non-attached microorganisms, the thalli were rinsed on both sides with $100 \mathrm{ml}$ of sterile seawater (SSW), and then were treated with a mixture of penicillin, chloramphenicol, polymixin and neomycin, namely the amount that was necessary to produce non-inhibition in population growth from the growth responses according to Nakanishi et al. (1996) and Jeong et al. (2000). The sterilized water used for algal cultivation was prepared according to the method 
of Jin and Dong (2003), and the pH and salinity were adjusted to 8.0 and 31, respectively. Treated blades were placed in empty, sterile bottles containing sterilized seawater enriched with $\mathrm{f} / 2$ culture medium and were allowed to adapt to the laboratory environment for $6 \mathrm{~d}$ before use. The culture medium changed every 3 days so that the growth conditions of all the collected the thalli were consistent. During the cultivation, the temperature was kept at $20 \pm$ $0.1{ }^{\circ} \mathrm{C}$ on a 12 -h light: dark cycle. Illumination was provided by cool-white fluorescent lamps at $80 \mu \mathrm{mol} \mathrm{m} \mathrm{m}^{-2} \cdot \mathrm{s}^{-1}$.

\subsection{Responses and Absorption of S. thunbergii to Different Concentrations of Nitrate and Phosphate: Experimental Design}

\subsubsection{Experimental Design}

Healthy blade at a fresh weight of $3.00 \pm 0.010 \mathrm{~g}$ were chosen and inoculated into $300 \mathrm{~mL}$ sterilized natural seawater. The whole experiment lasted for 6 days and the nutrient condition was adjusted by $\mathrm{NaNO}_{3} 、 \mathrm{KH}_{2} \mathrm{PO}_{4}$ to the setting concentrations listed in Table 1. The trace metal elements and vitamins were added just as the $\mathrm{f} / 2$ culture medium. The group cultured in $\mathrm{f} / 2$ medium was used as the control. Group without nutrient addition was used as the blank control. All other conditions and procedures in this experiment were the same as those described in 2.1. The fresh weight, the activities of NR and Alkaline Phosphatase (AKP) were analyzed on 0 day, $3^{\text {rd }}$ and $6^{\text {th }}$ day after exposure.

Table 1. The setting concentrations of nitrogen and phosphate in the test

\begin{tabular}{llll}
\hline & Concentrations of N $(\mu \mathrm{mol} / \mathrm{L})$ & Concentrations of $\mathrm{P}(\mu \mathrm{mol} / \mathrm{L})$ & $\mathrm{N} / \mathrm{P}$ ratio \\
\hline Nitrogen deficiency ( I ) & 0 & 16 & \\
Phosphate deficiency (II) & 80 & 0 & $1: 1$ \\
Phosphate enrichment (III) & 80 & 80 & $5: 1$ \\
Phosphate enrichment (IV) & 80 & 16 & $16: 1$ \\
f/2 medium (V) & 880 & 36 & $32: 1$ \\
Nitrogen enrichment (VI) & 80 & 2.5 & $32: 1$ \\
Nitrogen enrichment (VII) & 512 & 16 & \\
\hline
\end{tabular}

\subsubsection{Enzyme Activities Assay}

Samples (0.4-0.5 g FW) were ground in liquid nitrogen and extracted with $1.5 \mathrm{~mL} 50-\mathrm{mmol} / \mathrm{L}$ potassium phosphate buffer (pH7.4) containing 0.1-mmol/L EDTA. Extracts were centrifuged for $15 \mathrm{~min}$ at $15,000 \mathrm{rpm}$ at $4^{\circ} \mathrm{C}$. The supernatant, here referred as crude enzymatic extraction, was used for enzymatic activity assay. Alkaline phosphatase (AKP) activity was determined by the kits purchased from Nanjing Jiancheng Bioengineering institute (Nanjing, China). One unit of AKP activity was defined as enzyme reacts with base materials to produce $1 \mathrm{mg}$ phenols per cell during $15 \mathrm{~min}$ at $37^{\circ} \mathrm{C}$. The activity of nitrate reductase (NR) was determination according to the method of the original protocol of Berges and Harrison (1995) by spectrophotometric $\mathrm{NO}_{2}^{-}$detection at the end of incubation period. Rates of NR were 
normalized to the appropriate cell density at the time of enzyme sample collection to calculate cell-specific enzyme activity rates (Lomas, 2004).

All assays were performed at $20^{\circ} \mathrm{C}$. Results for AKP and NR ere expressed as units $(U)$ of enzyme activity per milligram of total soluble protein.

\subsubsection{Protein Assay}

Total soluble proteins of the crude extract for antioxidant enzyme activities were determined using a commercial Protein Assay (BioRad), based on the Bradford method (Bradford, 1976). Protein content was determined spectrophotometrically at $595 \mathrm{~nm}$ and concentrations were calculated compared with a standard of bovine serum albumin (SIGMA).

\subsubsection{Nutrient Assay}

Simultaneous assay on nutrient change in the culture medium during the experiment was performed. The procedures and conditions were exactly the same as described in 2.2.1 with an exception that the experimental volumn was expanded to $500 \mathrm{~mL}$. A $10-\mathrm{mL}$ water sample was collected from the co-culture every $24 \mathrm{~h}$ and was filtered through a membrane filters (Millipore, $0.45-\mu \mathrm{m}$ pore size). The nitrate and phosphate concentrations were analyzed according to the method of Jones (1984) and Hager et al. (1968) respectively. At the same time, $\mathrm{pH}$ values in the co-culture were estimated by using a portable $\mathrm{pH} \&$ temperature meter (HI 98128, Hanna Instrument Co. Ltd, Hanna, Italy).

\subsection{Statistics Assay}

Results were analyzed with the software package Sigmaplot 8.0 and SPSS 13.0. We calculated mean values and standard deviations from the different replicates per treatment (n $=3$ ), and the significance between the treated group and the control was analyzed by one-way ANOVA with significance set at $P<0.05$. Tukey tests $(\alpha=0.05)$ were used to group homogeneous means. Piror to assessment by ANOVA, all data were tested for normality (Kolmogorov Smirnor test, $\alpha=0.05$ ) (Mulderij et al., 2005).

\section{Results}

\subsection{Changes of the Fresh Weight Changes of S. thunbergiiis When Exposed to Different Nutrient Conditions}

The changes of the relative growth rate (RGR) of $S$. thunbergiiis varied greatly during the experiment (Table 2). The fresh weight increased a little during the first 3 days after exposure in groups of I, VI and VII and then decreased steadily till the end of the experiment. As to group II, III and V, the growth of $S$. thunbergiiis was obviously inhibited and the RGR was negative throughout the whole experiment. Results in this experiment inferred that high concentration of phosphate in the environment could inhibit the growth of $S$. thunbergiiis. 


\section{Macrothink}

Table 2. The changes of the RGR of $S$. thunbergiiis during the experiment

\begin{tabular}{lllllll}
\hline & $1 \mathrm{~d}$ & $2 \mathrm{~d}$ & $3 \mathrm{~d}$ & $4 \mathrm{~d}$ & $5 \mathrm{~d}$ & $6 \mathrm{~d}$ \\
\hline Blank & 0.028 & 0.053 & 0.106 & 0.124 & 0.096 & 0.0833 \\
Group I & 0.011 & 0.031 & 0.053 & 0.021 & -0.039 & -0.076 \\
Group II & -0.017 & -0.035 & -0.071 & -0.059 & -0.042 & -0.03267 \\
Group III & -0.049 & -0.064 & -0.15933 & -0.179 & -0.168 & -0.157 \\
Group IV & -0.017 & -0.016 & -0.06167 & -0.052 & -0.035 & -0.00667 \\
Group V & -0.018 & -0.025 & -0.08433 & -0.099 & -0.114 & -0.12533 \\
Group VI & 0.011 & 0.021 & 0.0327 & 0.043 & 0.065 & 0.0999 \\
GroupVII & 0.015 & 0.027 & 0.0468 & 0.034 & -0.019 & -0.192 \\
\hline
\end{tabular}

3.2 Changes of Nitrate and Phosphate Concentrations in the Culture Medium When Exposed to Different Nutrient Conditions

The changes of nitrate (Figure 1) concentrations in the culture medium were shown in Figure 2. The concentrations in all the treated groups decreased steadily with time increasing. In groups of nitrogen and phosphate enrichment, the nutrient concentrations in the culture medium decreased on the first 2-3 days after exposure and increased a little. Similar trend was observed in blades cultured in $\mathrm{f} / 2$ medium. However, quite different changes were found in such groups of nitrate deficiency as the blank control and nitrate enrichment group, which increased firstly and then decreased to some extent. Results in the present study inferred that $S$. thunbergiiis could luxuriously absorb the nutrients when they enough presented in the environment while released from blade to the environment when nutrient were deficient in the culture medium.

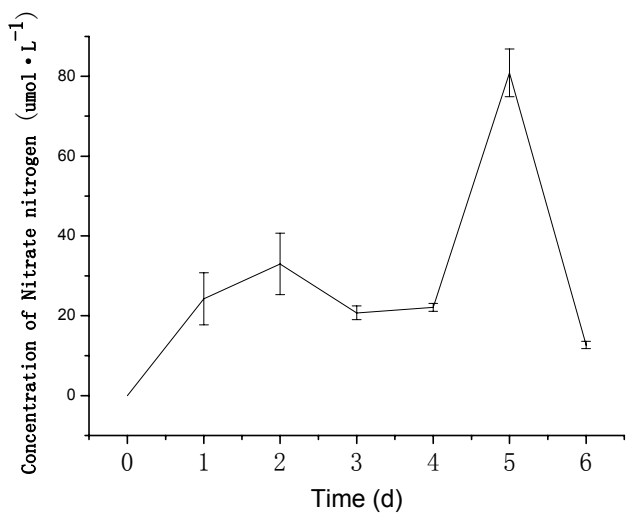

a. blank control

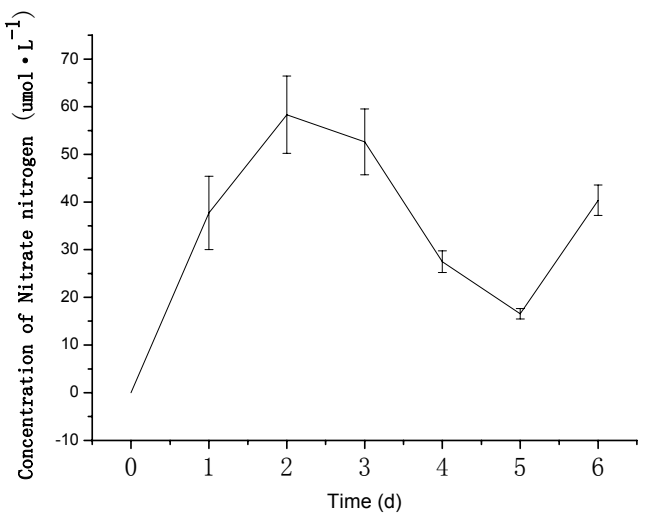

b. group I 


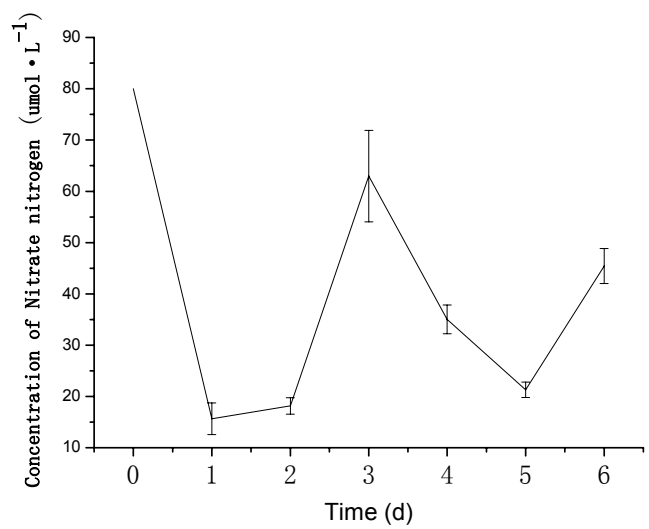

c. group II

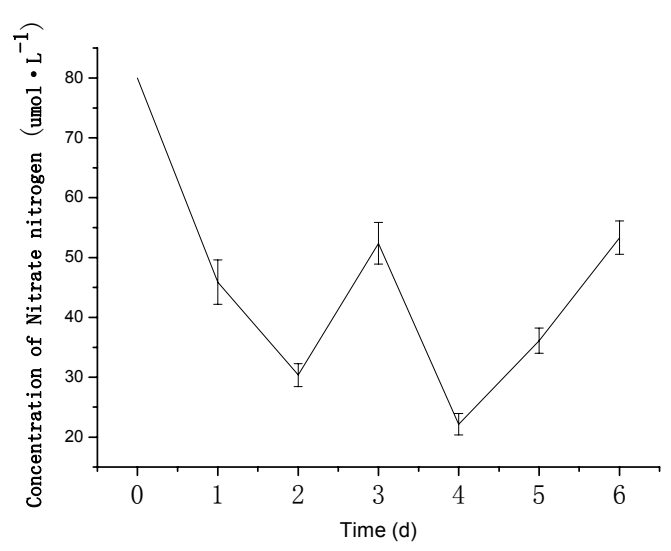

e. group IV

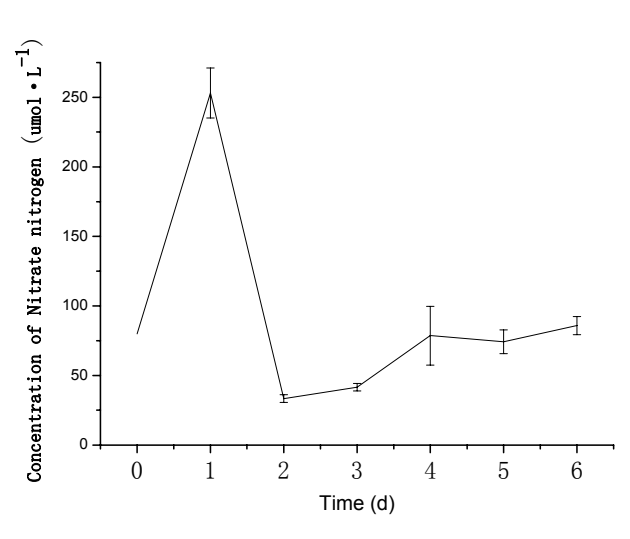

g. group VI

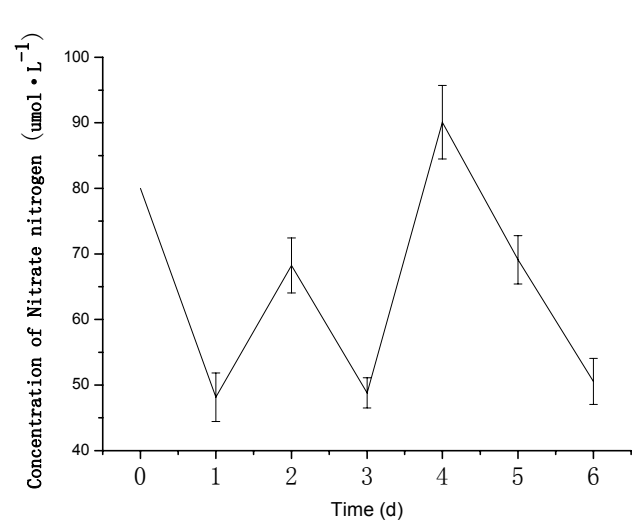

d. group III

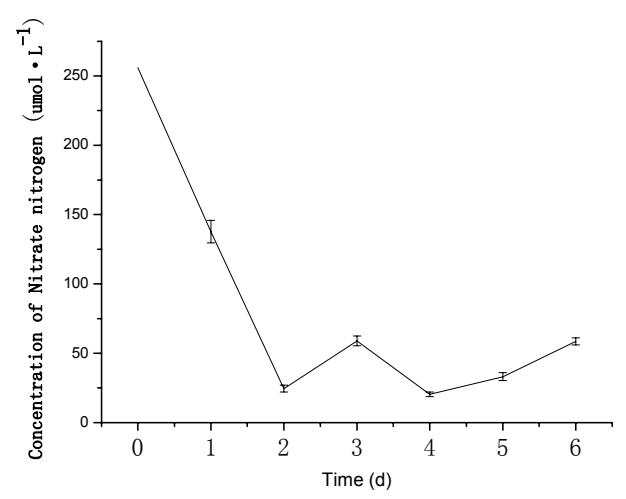

f. group $V$

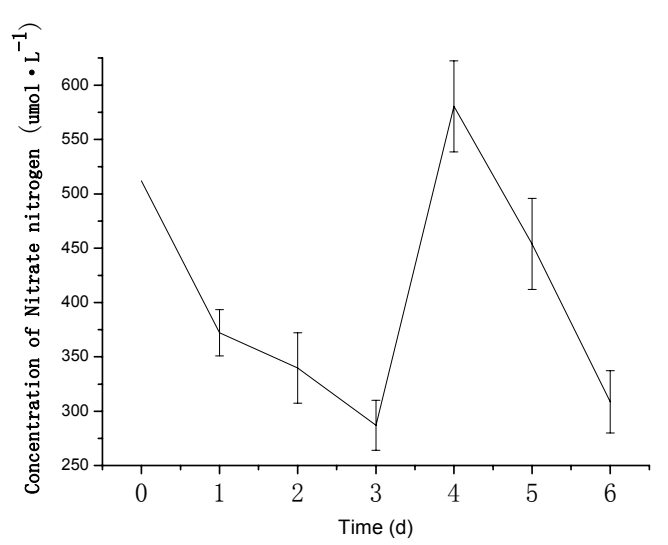

h. group VII

Figure 1. Changes of nitrate concentrations in different treatment groups 


\section{Macrothink}

Aquatic Science and Technology

ISSN 2168-9148

2014, Vol. 2, No. 2

Similar changing tendency of phosphate concentration in the culture medium during the experiment was observed, and the concentrations in either treated groups or the blank control decreased steadily during the experiment. Obvious significance was found between the initial concentrations and those of the end of the experiment $(\mathrm{P}<0.05)$ (Figure 2).

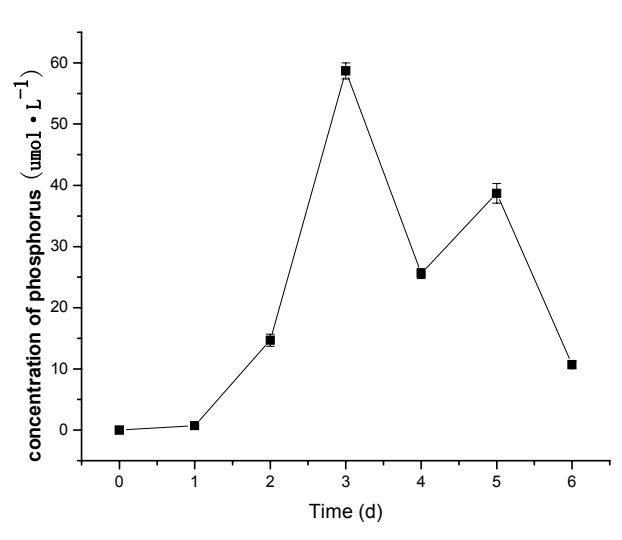

a. blank control

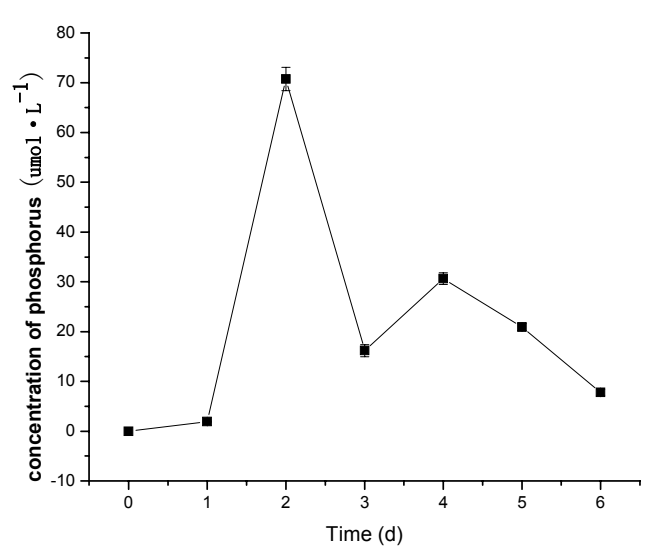

c. group II

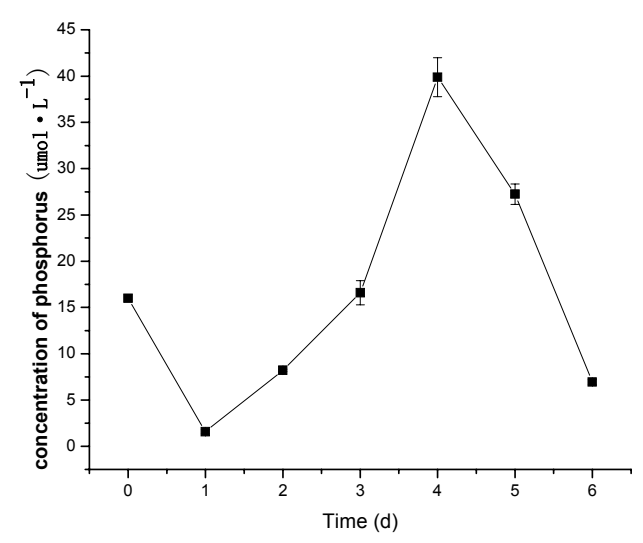

e. group IV

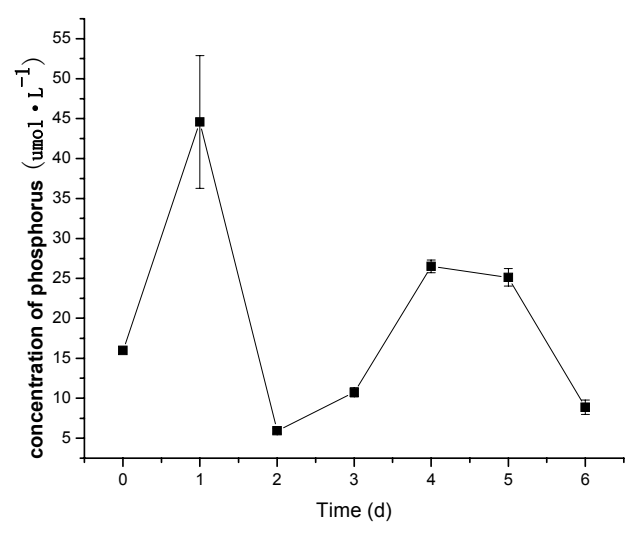

b. group I

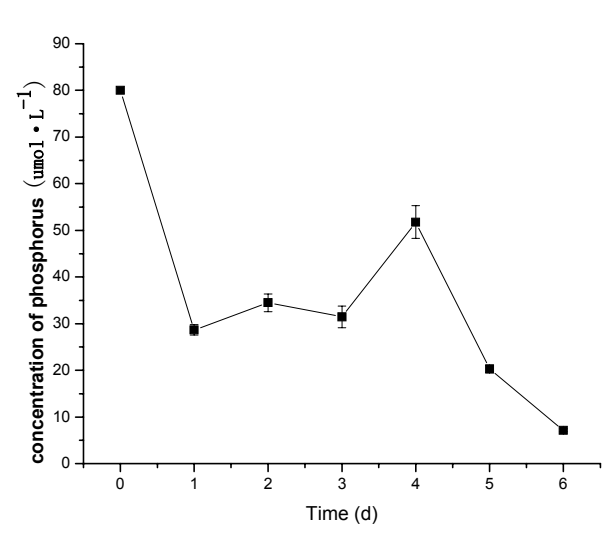

d. group III

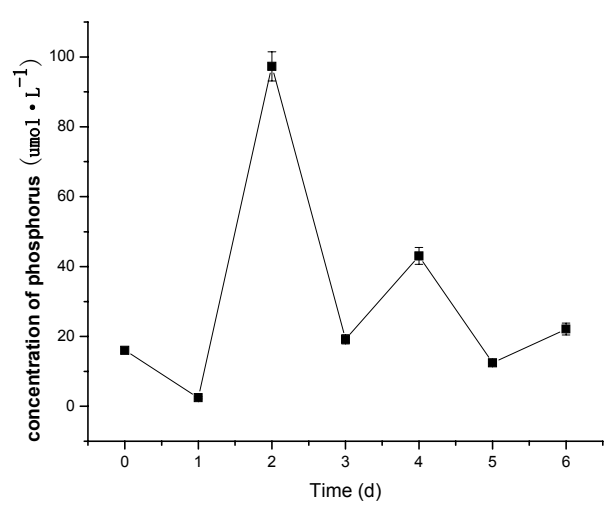

f. group V 


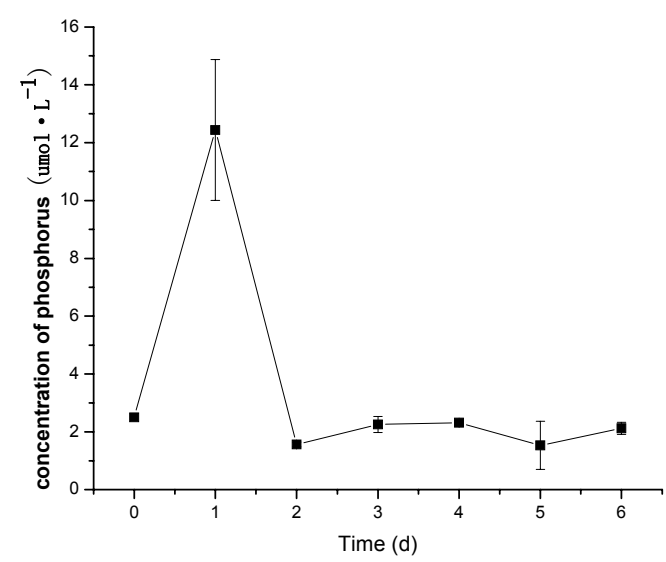

g. group VI

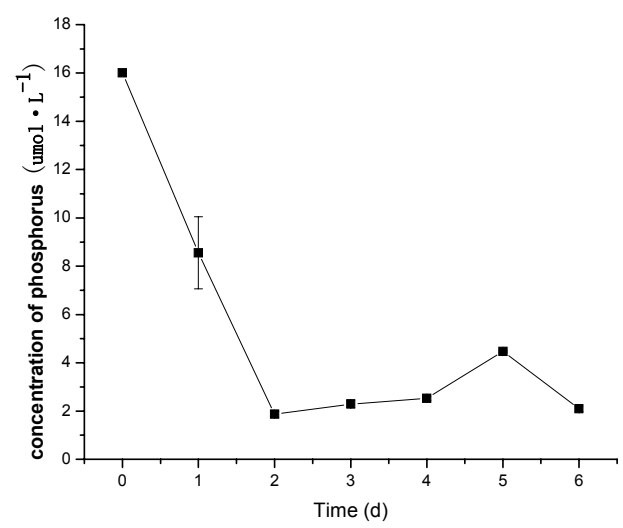

h. group VII

Figure 2. Changes of phosphate concentrations in different treatment groups

\subsection{Changes of NR and AKP Activities in S. thunbergiiis When Exposed to Different Nutrient Conditions}

Changes of NR activities in $S$. thunbergiiis when exposed to different nutrient conditions were shown in Figure 3. Activities in group IV and V increased a little at the beginning of the experiment and decreased thereafter. Different changing tendency was observed in group I, II and III which increased steadily till the end of the experiment. NR activity in group VII decreased till the end. Little change was observed in group VI during the experiment. Taking the activity on the third day for example: great difference was observed between the treated groups compared by $t$-test $(\mathrm{P}<0.05)$ except that between groups of I and III and between group of VI and VII which showed little difference.

Moreover, the initial concentrations of phosphate was $16 \mu \mathrm{mol} / \mathrm{L}$ in group of I 、 IV 、 $\mathrm{V}$ and VII, and the initial nitrate concentration in the group was $0 \mu \mathrm{mol} / \mathrm{L} 、 80 \mu \mathrm{mol} / \mathrm{L}, 256 \mu \mathrm{mol} / \mathrm{L}$, $512 \mu \mathrm{mol} / \mathrm{L}$ respectively. The order of NR activities in the groups was $\mathrm{VII}<\mathrm{I}<\mathrm{IV}<\mathrm{V}$, and the NR activity increased with the nitrate concentration increment in the culture medium. It seemed that there was a positive relation between the environmental nitrate concentration and the NR activity. On the $6^{\text {th }}$ day after exposure, significance was observed between all groups $(\mathrm{P}<0.05, t$-test $)$ except that of the blank control and group $\mathrm{V}$, and the order of NR activity was $\mathrm{VII}<\mathrm{IV}<\mathrm{V}<\mathrm{I}$. NR activity in group of IV, V and VII decreased significantly by about $59.1 \%, 65.2 \%$ and $51.6 \%$ as compared to that on the $3^{\text {rd }}$ day after treatment. Results indicated that different concentrations of nitrate and N/P ratio affected NR activity greatly. NR in group VI and VII kept low throughout the experiment indicating that nitrate enrichment or relatively higher concentration of nitrate would inhibit NR activity. 


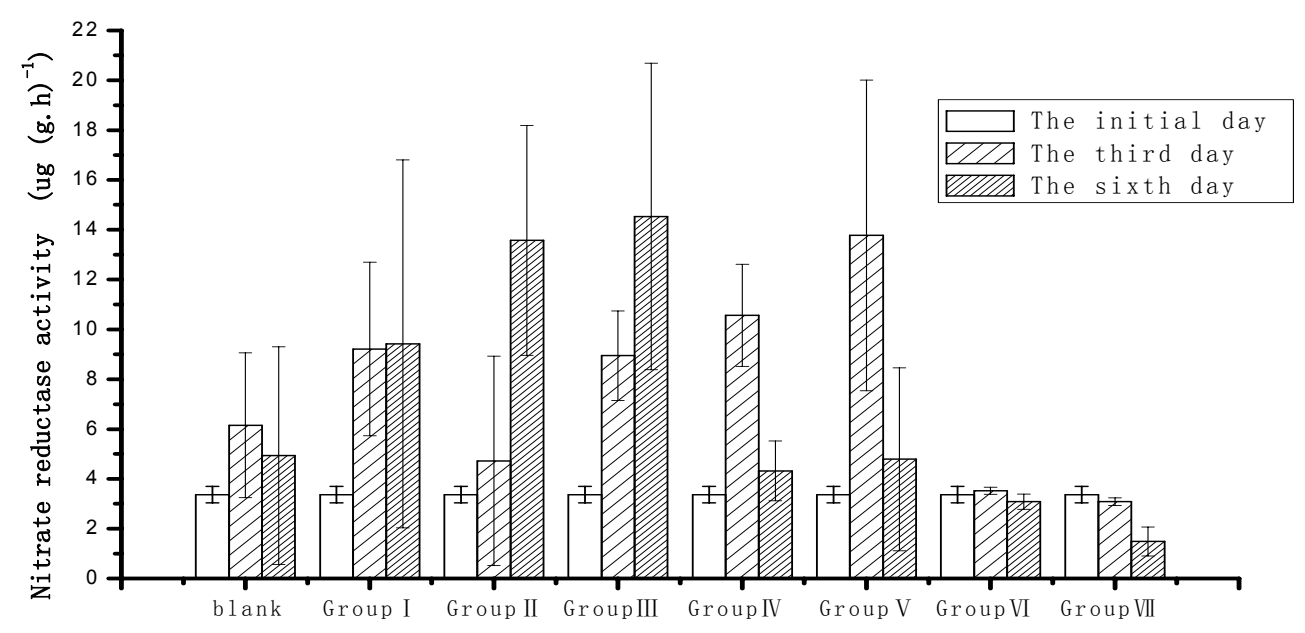

Figure 3. Activity of nitrate reductase (NR) in different treatment groups

Changes of AKP when exposed to different nutrient conditions were shown in Figure 4. Results demonstrated that AKP in control blank and group III increased firstly and then decreased a little. Opposite changing tendency was observed in group I and VI which decreased firstly and then decreased. AKP activity in other treated group decrease steadily with time increasing. Moreover, paired t-test showed significant difference between treated groups and the blank control at any set time indicating that the phosphate concentration and $\mathrm{N} / \mathrm{P}$ ratio in the culture medium exerted effect on AKP activity. Taking group of II V VIVIV and III for example: the initial nitrate concentration was $80 \mu \mathrm{mol} / \mathrm{L}$ and the phosphate concentration was $0 \mu \mathrm{mol} / \mathrm{L}, 2.5 \mu \mathrm{mol} / \mathrm{L}, 16 \mu \mathrm{mol} / \mathrm{L}$ and $80 \mu \mathrm{mol} / \mathrm{L}$, respectively. AKP activity in group II and VI on the $6^{\text {th }}$ day after treatment was higher than that on the $3^{\text {rd }}$ day while that of group IV and III on the $6^{\text {th }}$ day was lower than that on the $3^{\text {rd }}$ day. The possible reason was that the phosphate concentration was limited in group II and VI and AKP was induced. Contrarily, high concentration of phosphate in the environment would inhibit the induction of AKP activity, which was indicated in group III and IV (Figure 4). 


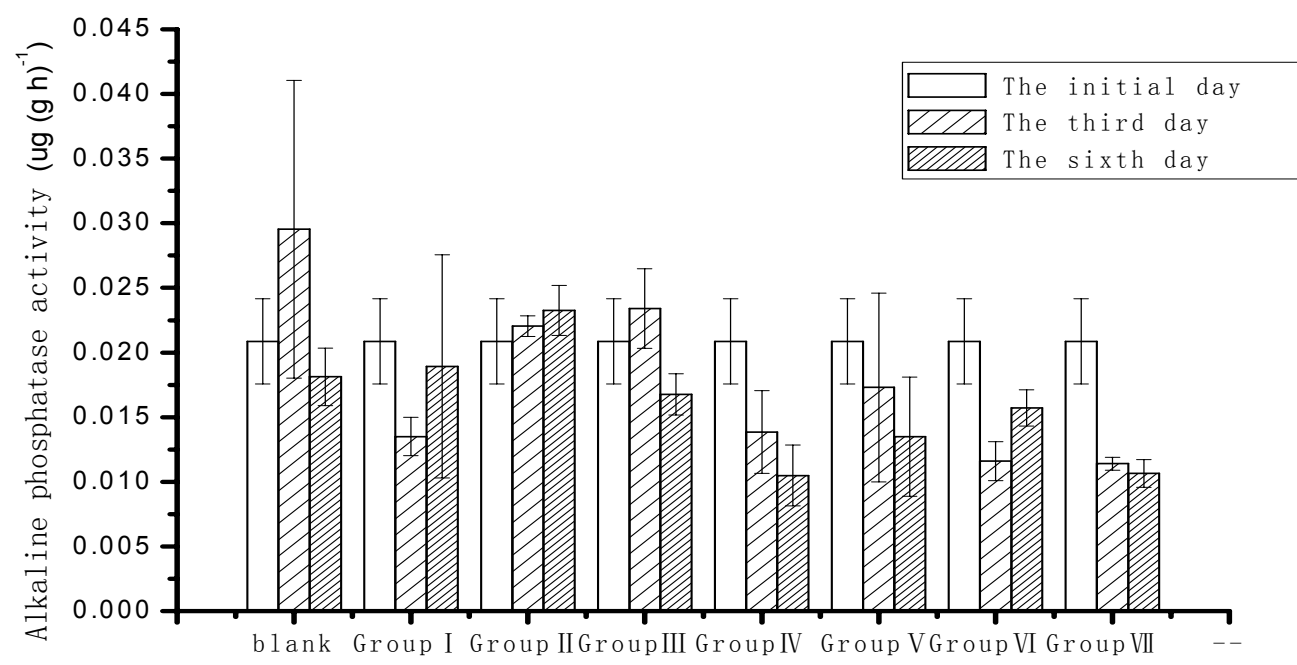

Figure 4. Changes of alkaline phosphatase activities when exposed to different nutrient conditions

\section{Discussion}

Different concentration of phosphate and nitrate as well as different $\mathrm{N} / \mathrm{P}$ ratio in the environment would exert different effects on growth of $S$. thunbergii. The macroalgal growth was significantly affected and the fresh weight decreased. Moreover, enzymatic activities that relate to the nutrient mechanism were affected and a relatively obvious changing tendency was observed between the environment concentration of nutrient and the enzymatic activities. It had been reported that different environmental nutrient conditions exerted impact on nutrient uptake mechanism or damage to enzyme involved in the $\mathrm{N}$ or P metabolism in algae (Shelly et al., 2005).

Nitrogen is the necessary elements for algal growth. Nitrate reductase (Nitrate reductase, NR) is one of the key enzyme of nitrogen metabolism and it is also a rate-limiting enzyme controlling the whole process of assimilation. When plants absorb $\mathrm{NO}_{3}{ }^{-}$in the environment, $\mathrm{NR}$ would play role in transfer $\mathrm{NO}_{3}{ }^{-}$to $\mathrm{NO}_{2}{ }^{-}$and then the nitrite reductase (NIR) reduce it to $\mathrm{NH}_{4}{ }^{+}$. Only basing the procedures above mentioned, it could involve in the synthesis of amino acids and proteins. NR activity is susceptible to the external factors such as $\mathrm{NO}_{3}{ }^{-}$ concentration in the environment which is the substrates of the reaction of NR reduction. Thus, $\mathrm{NO}_{3}{ }^{-}$is suggested to be the optimum factor for NR induction. NR activity is very low if $\mathrm{NO}_{3}{ }^{-}$in the environment was low or limited while it increased immediately if extra $\mathrm{NO}_{3}{ }^{-}$is added onto the medium. That was why we observed the fluctuation of NR activity in the present study.

Alkaline Phosphatase (AP) is a kind of non-specific hydrolase and could hydrolyze the phosphate into inorganic phosphoric acid and the corresponding alcohols, phenolic 
compounds and sugar. AP is widespread in bacteria, fungi, algae, and animals and has been reported to be involved in cellular phosphorus metabolism. It plays essential role in the biogeochemical cycle of phosphate. Numerous studies have demonstrated that the extracellular alkaline phosphatase phytoplankton or bacteria could catalse phosphate ester compounds to hydrolyze into orthophosphate, which is one of the most important supplemental way of phosphate in the water. In natural seawater, the environmental factors would significantly affect AKP activity: there is a negative co-relative between the AKP activity and the environmental concentation of phosphate. That means AKP could be induced to relatively higher activity when the phosphate concentration is low in the water and this mechanism is called "inhibition-induction mechanism". Therefore, AKP fluctuated with the changes of the environmental phosphate concentrations. Durin the 6 days of experiment, either nitrate or phosphate presented fluctuation and the environmental nutrients might play decisive role in nutrient-absorption of $S$. thunbergiiis.

\section{Conclusion}

The activity of NR and AKP fluctuated with the environmental concentrations of phosphate and nitrate and a relatively clear relationship was observed between the enzymatic changes and the environmental concentrations. However, NR and AKP demonstrated different changing tendency when $S$. thunbergiiis was exposed to different nutrient conditions, suggesting the co-existent mechanism of absorption and release of nitrate and phosphate in $S$. thunbergiiis.

\section{Acknowledgments}

The present study was partially supported by scientific research fund of Harbin Institute of Technology at Weihai (project number HIT(WH)201202). The authors are thankful to professor Wang You and ecological laboratory of Ocean University of China for their technical assistance in laboratory work.

\section{References}

Anderson, D. M. (1997). Turning back the harmful red tide. Nature, 388, 513-514. http://dx.doi.org/10.1038/41415

Berges, J. A., \& Harrison, P. J. (1995). Nitrate reductase activity quanti-tatively predicts the rate of nitrate incorporation under steady state light limitation: a revised assay and characterization of the enzyme in three species of marine phytoplankton. Limnol Oceanogr, 40, 82-93. http://dx.doi.org/10.4319/10.1995.40.1.0082

Bradford, M. M. (1976). A rapid and sensitive method for the quantification of micrograms quantities of protein utilizing the principle of protein-dye binding. Anal Biochem, 72, 248-254. http://dx.doi.org/10.1016/0003-2697(76)90527-3

Chung, I. K., Kang, Y. H., Yarish, C., et al. (2002). Application of seaweed cultivation to the bioremediation of nutrient-rich effluent. Algae, 17(3), 187-194. http://dx.doi.org/10.4490/ALGAE.2002.17.3.187 
Hager, S. W., Gordon, L. I., \& Park, P. K. (1968). A practical manual for the use of Technicon Autoanalyzer in seawater nutrient analysis. A final report to B.C.F. Contract 1-1-17-0001-1759, October 1968.

Jeong, J. H., Jin, H. J., Sohn, C. H., Suh, K. H., \& Hon, Y. K. (2000). Algicidal activity of the macroalga Corallina pilulifera against red tide microalgae. J. Appl. Phycol., 12, 37-43. http://dx.doi.org/10.1023/A:1008139129057

Jin, Q., \& Dong, S. L. (2003). Comparative studies on the allelopathic effects of two different strains of $U$. pertusa on Heterosigma akashiwo and Alexandrium tamarense. J. Exp. Mar. Biol. Ecol., 293, 41-55. http://dx.doi.org/10.1016/S0022-0981(03)00214-4

Lomas, M. W. (2004). Nitrate reductase and urease enzyme activity in the marine diatom Thalassiosira weissflogii (Bacillariophyceae): interactions among nitrogen substrates. Marine Biology, 144, 37-44. http://dx.doi.org/10.1007/s00227-003-1181-x

Mcvey, J. P., Stickney, R. R., Yarish, C., et al. (2002). Aquatic polyculture and balanced ecosystem management: New paradigms for seaweed production. In Responsible marine aquaculture (pp. 91-104). New York: CABI Publishing. http://dx.doi.org/10.1079/9780851996042.0091

Mulderij, G., Mooij, W. M., Smolders, A. J. P., \& Van Donk, E. (2005). Allelopathic inhibition of phytoplankton by exudates from Stratiotes aloides. Aquat. Bot., 82, 284-296. http://dx.doi.org/10.1016/j.aquabot.2005.04.001

Nakanishi, K., Nishijima, M., Nishimura, M., Kuwano, K., \& Saga N. (1996). Bacteria that induce morphogenesis in Ulva pertusa (Chlorophyta) brown under axenic conditions. $J$. Phycol., 32(3), 479-482. http://dx.doi.org/10.1111/j.0022-3646.1996.00479.x

Shelly, K., Roberts, S., Heraud, P., \& Beardall, J. (2005). Interactions between UV-B exposure and phosphorus nutrition. I Effects on growth, phosphate uptake, and chlorophyll fluorescence. J Phycol, 41, 1204-1211. http://dx.doi.org/10.1111/j.1529-8817.2005.00148.x

Zhang, Q. S., Li, W., Liu, S., \& Pan, J. H. (2009). Size-dependence of reproductive allocation of Sargassum thunbergii (Sargassaceae, Phaeophyta) in Bohai Bay, China. Aquatic Botany, 91, 194-198. http://dx.doi.org/10.1016/j.aquabot.2009.06.003

\section{Copyright Disclaimer}

Copyright reserved by the author(s).

This article is an open-access article distributed under the terms and conditions of the Creative Commons Attribution license (http://creativecommons.org/licenses/by/3.0/). 